\title{
TRANSFORMASI GIVENS DAN PENERAPANNYA
}

\author{
Dwi Oktaviana, Evi Noviani, Fransiskus Fran
}

\begin{abstract}
INTISARI
Transformasi Givens merupakan transformasi linear yang menggunakan matriks rotasi Givens. Matriks rotasi Givens dibentuk dari perluasan matriks rotasi pada dimensi dua. Matriks tersebut merupakan sebuah matriks yang ortogonal dan banyak digunakan dalam aljabar numerik. Dua di antara penerapan transformasi Givens yang dibahas pada penelitian ini yaitu pembentukan dekomposisi QR dari sebarang matriks dan penentuan nilai eigen dari matriks persegi. Dekomposisi QR dari sebuah matriks adalah sebuah dekomposisi $\mathbf{A}=\mathbf{Q R}$, dengan $\mathbf{Q}$ adalah sebuah matriks persegi yang ortogonal dan $\mathbf{R}$ adalah sebuah matriks segitiga atas. Nilai eigen yang diperoleh dengan menggunakan transformasi Givens adalah nilai pada entri diagonal utama dari matriks segitiga atas A yang telah ditransformasi dengan matriks rotasi Givens.
\end{abstract}

Kata Kunci: rotasi Givens, dekomposisi QR, nilai eigen

\section{PENDAHULUAN}

Transformasi linear didefinisikan sebagai suatu pemetaan dari suatu ruang vektor ke ruang vektor lainnya yang memenuhi sifat homogenitas dan sifat penjumlahan [1]. Transformasi linear juga disebut sebagai sebuah fungsi dari suatu ruang vektor ke ruang vektor lainnya yang mengawetkan operasi penjumlahan dan perkalian skalar. Satu di antara pemetaan yang memenuhi definisi dari transformasi linear yaitu rotasi.

Rotasi merupakan perputaran suatu objek dengan sumbu tetap. Pada dimensi dua, dapat didefinisikan dua buah matriks rotasi terhadap arah putarnya, yaitu diputar berlawanan dengan arah jarum jam dan searah dengan jarum jam. Pada dimensi tiga, rotasi dilakukan terhadap salah satu sumbu pada dimensi tiga, yaitu sumbu $x, y$, atau $z$. Rotasi pada dimensi dua dan tiga, dapat digambarkan dalam bentuk ilustrasi dengan titik awal dan titik hasilnya. Titik awal, titik hasil, beserta sudut rotasi yang dilakukan akan membentuk suatu potongan lingkaran dengan besar sudut yang digunakan.

Misalkan $T: \mathbb{R}^{n} \rightarrow \mathbb{R}^{m}$ merupakan sebuah transformasi linear, maka terdapat suatu $\mathbf{A} \in \mathbf{M}(\mathbb{R})$ sedemikian sehingga $T(\boldsymbol{x})=\mathbf{A} \boldsymbol{x}$ untuk setiap $\boldsymbol{x} \in \mathbb{R}^{n}$ dapat ditransformasikan ke $\mathbb{R}^{m}$. Terdapat beberapa contoh matriks yang memenuhi transformasi linear. Satu di antaranya adalah matriks rotasi. Untuk rotasi yang diperluas pada dimensi- $n$, dapat dipelajari dan dianalisis secara aljabar. Perluasan matriks rotasi, yang dinamai rotasi Givens, ditemukan oleh seorang metematikawan bernama James Wallace Givens pada tahun 1950-an. Matriks rotasi Givens ini kemudian banyak digunakan untuk memecahkan permasalahan pada aljabar linear numerik [1].

Rotasi Givens merupakan sebuah matriks yang ortogonal sehingga dapat digunakan untuk menentukan dekomposisi QR dari sebarang matriks $n \times m$. Matriks rotasi Givens juga dapat digunakan untuk menentukan nilai eigen dari suatu matriks persegi dengan menggunakan dekomposisi QR. Saat ini nilai eigen memiliki aplikasi dalam berbagai bidang seperti transformasi matriks, grafik komputer, getaran mekanis, aliran panas, dinamika populasi, mekanika kuantum, dan ekonomi [1].

Adapun langkah yang dilakukan pada penelitian ini yaitu dengan mempelajari dasar dari rotasi pada dimensi dua. Kemudian dibentuk rotasi pada dimensi tiga dengan memperhatikan analisis pada 
dimensi dua. Setelah itu matriks rotasi diperluas untuk dimensi- $n$. Matriks rotasi pada dimensi- $n$ disebut sebagai matriks rotasi Givens. Matriks rotasi Givens memenuhi definisi transformasi linear, sehingga kemudian akan disebut sebagai transformasi Givens.

Transformasi Givens dapat digunakan untuk menentukan dekomposisi QR dari suatu matriks. Perhitungan tersebut menghasilkan faktorisasi dari matriks awal menjadi perkalian dua buah matriks $\mathbf{Q}$ dan $\mathbf{R}$ dengan $\mathbf{Q}$ adalah sebuah matriks ortogonal, dan $\mathbf{R}$ merupakan matriks segitiga atas. Jika matriks A yang digunakan adalah matriks persegi, maka matriks $\mathbf{A}$ dapat dihitung nilai eigennya dengan menggunakan transformasi Givens.

\section{TRANSFORMASI LINEAR}

Definisi 1 [1] Jika $T: V \rightarrow W$ adalah sebuah fungsi dari sebuah ruang vektor $V$ ke sebuah ruang vektor $W$, maka $T$ disebut sebagai transformasi linier dari $V$ ke $W$ jika dua sifat berikut berlaku untuk semua vektor $\boldsymbol{u}$ dan $\boldsymbol{v}$ pada $V$ dan untuk semua skalar $k$ :

1. $\quad T(k \boldsymbol{u})=k T(\boldsymbol{u})$ (Sifat homogenitas)

2. $T(\boldsymbol{u}+\boldsymbol{v})=T(\boldsymbol{u})+T(\boldsymbol{v})$ (Sifat penjumlahan)

Sifat homogenitas dan sifat penjumlahan dari transformasi linier $T: V \rightarrow W$ dapat dikombinasikan untuk menunjukkan bahwa jika $\boldsymbol{v}_{\mathbf{1}}, \boldsymbol{v}_{\mathbf{2}} \in V$ dan sebarang skalar $k_{1}, k_{2} \in \mathbb{R}$, maka

$$
T\left(k_{1} \boldsymbol{v}_{\mathbf{1}}+k_{2} \boldsymbol{v}_{\mathbf{2}}\right)=k_{1} T\left(\boldsymbol{v}_{\mathbf{1}}\right)+k_{2} T\left(\boldsymbol{v}_{2}\right)
$$

Secara umum, jika $\boldsymbol{v}_{\mathbf{1}}, \boldsymbol{v}_{2}, \ldots, \boldsymbol{v}_{\boldsymbol{n}} \in V$ dan $k_{1}, k_{2}, \ldots, k_{n}$ sebarang skalar, maka

$$
T\left(k_{1} \boldsymbol{v}_{\mathbf{1}}+k_{2} \boldsymbol{v}_{2}+\cdots+k_{n} \boldsymbol{v}_{\boldsymbol{n}}\right)=k_{1} T\left(\boldsymbol{v}_{\mathbf{1}}\right)+k_{2} T\left(\boldsymbol{v}_{2}\right)+\cdots+k_{n} T\left(\boldsymbol{v}_{\boldsymbol{n}}\right)
$$

Suatu transformasi linier juga dapat direpresentasikan dalam bentuk suatu matriks. Misalkan terdapat suatu matriks $\mathbf{A} \in \mathbf{M}_{m \times n}(\mathbb{R})$ dan didefinisikan suatu fungsi $T_{A}: \mathbb{R}^{n} \rightarrow \mathbb{R}^{m}$ oleh $T_{A}(\boldsymbol{x})=A \boldsymbol{x}$ untuk setiap $\boldsymbol{x} \in \mathbb{R}^{n}$. Dengan menggunakan sifat perkalian matriks, maka untuk setiap $\boldsymbol{x}, \boldsymbol{y} \in \mathbb{R}^{n}$ dan $k \in \mathbb{R}$ diperoleh:

$$
\begin{aligned}
T_{\mathbf{A}}\left(k_{1} \boldsymbol{x}+k_{2} \boldsymbol{y}\right) & =\mathbf{A}\left(k_{1} \boldsymbol{x}+k_{2} \boldsymbol{y}\right) \\
& =\mathbf{A}\left(k_{1} \boldsymbol{x}\right)+\mathbf{A}\left(\boldsymbol{k}_{2} \boldsymbol{y}\right) \\
& =k_{1} \mathbf{A}(\boldsymbol{x})+k_{2} \mathbf{A}(\boldsymbol{y}) \\
& =k_{1} T_{\mathbf{A}}(\boldsymbol{x})+k_{2} T_{\mathbf{A}}(\boldsymbol{y})
\end{aligned}
$$

Oleh karena itu, $T_{A}$ adalah transformasi linier dan dinamakan transformasi matriks.

\section{TRANSFORMASI GIVENS}

Transformasi Givens merupakan transformasi linear yang menggunakan matriks rotasi Givens. Matriks rotasi Givens merupakan sebuah matriks yang diperoleh dari perluasan matriks rotasi dari dimensi dua. Untuk membentuk matriks rotasi Givens, terlebih dahulu harus dipahami rotasi pada dimensi dua. Ilustrasi untuk rotasi pada dimensi dua dapat diperhatikan pada Gambar 1 berikut.

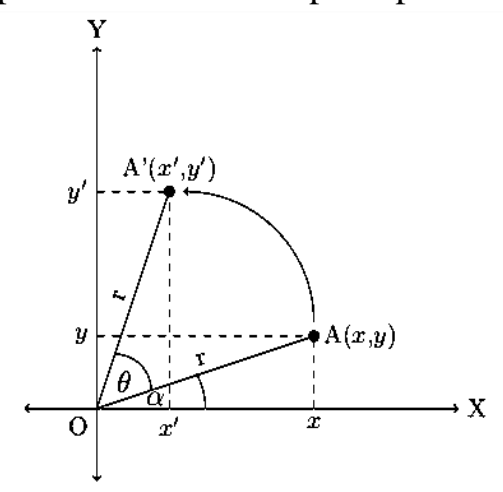

Gambar 1 Rotasi pada dimensi dua

Berdasarkan Gambar 1, dapat diketahui bahwa:

$$
x=r \cos \alpha
$$




$$
\begin{aligned}
& y=r \sin \alpha \\
& x^{\prime}=r \cos (\alpha+\theta) \\
& y^{\prime}=r \sin (\alpha+\theta)
\end{aligned}
$$

Selanjutnya, dicari persamaan untuk mendapatkan bayangan nilai $x$ dan $y$ setelah dilakukan rotasi. Untuk mendapatkan nilai $x^{\prime}$, menggunakan persamaan sebagai berikut:

$$
\begin{aligned}
x^{\prime} & =r \cos (\alpha+\theta) \\
& =r \cos \alpha \cos \theta-r \sin \alpha \sin \theta \\
& =x \cos \theta-y \sin \theta
\end{aligned}
$$

Selanjutnya, dicari persamaan untuk mendapatkan $y^{\prime}$ sebagai berikut:

$$
\begin{aligned}
y^{\prime} & =r \sin (\alpha+\theta) \\
& =r \sin \alpha \cos \theta+r \cos \alpha \sin \theta \\
& =x \sin \theta+y \cos \theta
\end{aligned}
$$

Sehingga diperoleh nilai $x^{\prime}$ dan $y^{\prime}$ sebagai berikut:

$$
\begin{aligned}
& x^{\prime}=x \cos \theta-y \sin \theta \\
& y^{\prime}=x \sin \theta+y \cos \theta
\end{aligned}
$$

Persamaan $x^{\prime}$ dan $y^{\prime}$ dapat direpresentasikan dalam bentuk matriks sebagai berikut:

$$
\left(\begin{array}{l}
x^{\prime} \\
y^{\prime}
\end{array}\right)=\left(\begin{array}{cc}
\cos \theta & -\sin \theta \\
\sin \theta & \cos \theta
\end{array}\right)\left(\begin{array}{l}
x \\
y
\end{array}\right)
$$

Selanjutnya, analisis transformasi rotasi pada dimensi tiga berkaitan dengan rotasi pada dimensi dua. Penentuan persamaan titik baru didasarkan pada analisis pada dimensi dua. Untuk rotasi pada $\mathbb{R}^{3}$, arah putar rotasi dilakukan terhadap pada sumbu yang terdapat pada dimensi tiga. Sumbu yang terdapat pada $\mathbb{R}^{3}$ dinamai sumbu $x, y$, dan $z$. Titik akan diputar terhadap sumbu yang terdapat di $\mathbb{R}^{3}$ sebesar $\theta$ sehingga akan terdapat tiga kondisi rotasi di ruang $\mathbb{R}^{3}$, yaitu rotasi terhadap sumbu- $x$, rotasi terhadap sumbu- $y$, dan rotasi terhadap sumbu- $z$.

Untuk rotasi pada sumbu- $x$, dapat digambarkan sebagai berikut.

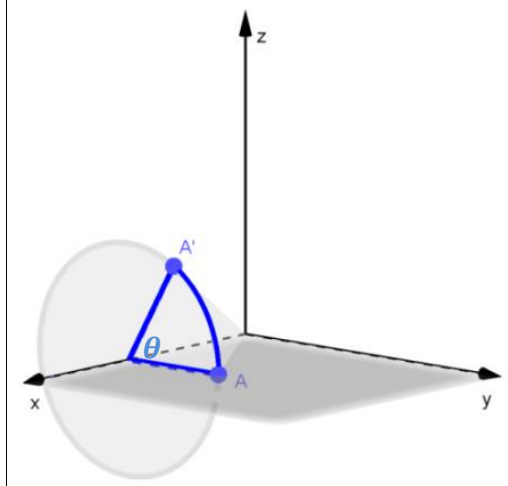

Gambar 2 Rotasi terhadap sumbu- $x$

Berikut hasil analisis rotasi terhadap sumbu- $x$.

$$
\begin{aligned}
& x^{\prime}=x \\
& y^{\prime}=y \cos \theta-z \sin \theta \\
& z^{\prime}=y \sin \theta+z \cos \theta
\end{aligned}
$$

Ketiga persamaan $x^{\prime}, y^{\prime}$, dan $z^{\prime}$ dapat direpresentasikan dalam bentuk matriks sebagai berikut.

$$
\left(\begin{array}{l}
x^{\prime} \\
y^{\prime} \\
z^{\prime}
\end{array}\right)=\left(\begin{array}{ccc}
1 & 0 & 0 \\
0 & \cos \theta & -\sin \theta \\
0 & \sin \theta & \cos \theta
\end{array}\right)\left(\begin{array}{l}
x \\
y \\
z
\end{array}\right)
$$

Kemudian untuk rotasi terhadap sumbu- $y$, dapat digambarkan sebagai berikut. 


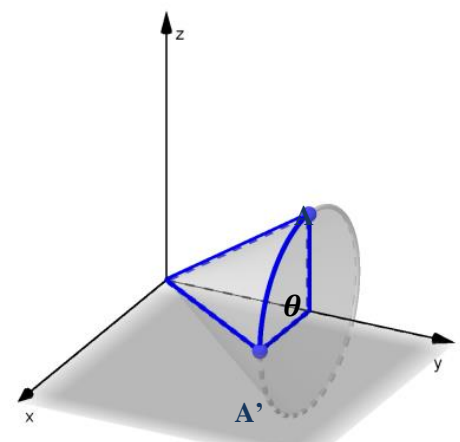

\section{Gambar 3 Rotasi terhadap sumbu-y}

Analisis rotasi terhadap sumbu- $y$ dapat dituliskan sebagai berikut.

$$
\begin{aligned}
& x^{\prime}=x \cos \theta+z \sin \theta \\
& y^{\prime}=y \\
& z^{\prime}=-x \sin \theta+z \cos \theta
\end{aligned}
$$

Ketiga persamaan $x^{\prime}, y^{\prime}$, dan $z^{\prime}$ jika dituliskan dalam bentuk matriks akan menjadi seperti berikut.

$$
\left(\begin{array}{l}
x^{\prime} \\
y^{\prime} \\
z^{\prime}
\end{array}\right)=\left(\begin{array}{ccc}
\cos \theta & 0 & \sin \theta \\
0 & 1 & 0 \\
-\sin \theta & 0 & \cos \theta
\end{array}\right)\left(\begin{array}{l}
x \\
y \\
z
\end{array}\right)
$$

Kemudian untuk rotasi terhadap sumbu- $z$, dapat dilihat pada gambar berikut.

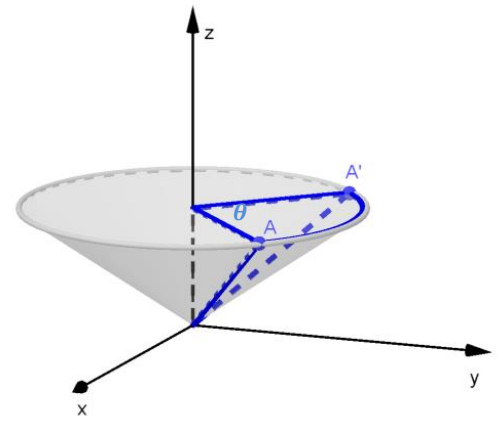

\section{Gambar 4 Rotasi terhadap sumbu-Z}

Berikut hasil analisis rotasi terhadap sumbu- $z$.

$$
\begin{aligned}
& x^{\prime}=x \cos \theta-y \sin \theta \\
& y^{\prime}=x \sin \theta+y \cos \theta \\
& z^{\prime}=z
\end{aligned}
$$

Jika dituliskan dalam bentuk matriks, menjadi sebagai berikut.

$$
\left(\begin{array}{l}
x^{\prime} \\
y^{\prime} \\
z^{\prime}
\end{array}\right)=\left(\begin{array}{ccc}
\cos \theta & -\sin \theta & 0 \\
\sin \theta & \cos \theta & 0 \\
0 & 0 & 1
\end{array}\right)\left(\begin{array}{l}
x \\
y \\
z
\end{array}\right)
$$

Rotasi pada dimensi- $n$ dapat digeneralisasi berdasarkan rotasi pada dimensi dua dan tiga. Misalnya, rotasi di sumbu- $y$ adalah rotasi di bidang- $x z$ yang diperoleh dari mengkonstruksi matriks

ke dalam posisi $x z$ dari $\mathbf{I}_{3 \times 3}$ sehingga menjadi

$$
\left(\begin{array}{cc}
\cos \theta & \sin \theta \\
-\sin \theta & \cos \theta
\end{array}\right)
$$

$$
\mathbf{P}_{y}=\left(\begin{array}{ccc}
\cos \theta & 0 & \sin \theta \\
0 & 1 & 0 \\
-\sin \theta & 0 & \cos \theta
\end{array}\right)
$$

Analisis tersebut kemudian dapat diaplikasikan untuk rotasi pada dimensi- $n$ sebagai berikut. 


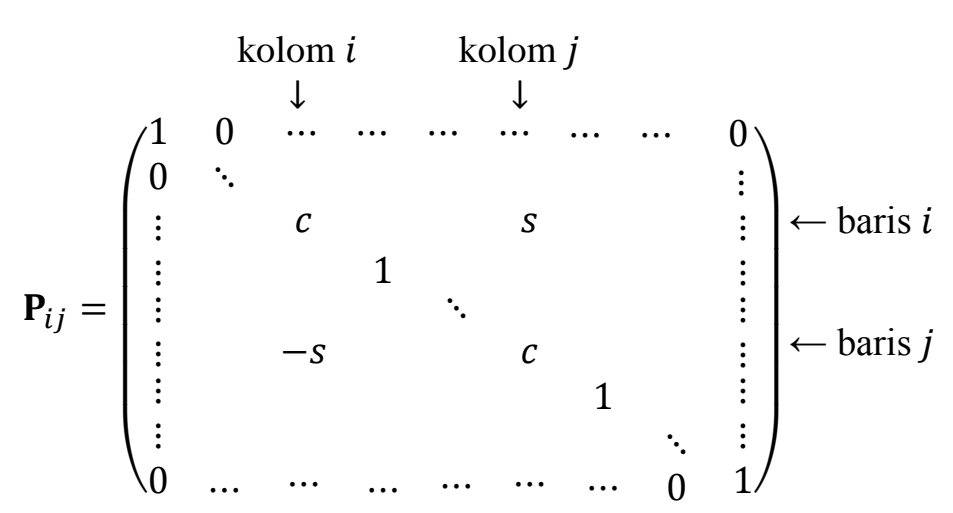

Matriks $\mathbf{P}_{i j}$ disebut sebagai matriks rotasi bidang (plane rotation matrices) karena digunakan untuk merotasi bidang- $(i, j)$ dari $\mathbb{R}^{n}$. Entri selain diagonal utama, $c$, dan $s$ pada matriks $\mathbf{P}_{i j}$ bernilai nol. Entri $c$ dan $s$ pada matriks $\mathbf{P}_{i j}$ merupakan simbol untuk sinus dan cosinus, masing-masing terhadap sudut $\theta$. Akan tetapi, tidak seperti rotasi pada dimensi dua dan tiga yang merotasi terhadap sudut $\theta$, hal tersebut tidak berlaku untuk dimensi- $n$. Pada dimensi- $n$, nilai $c$ dan $s$ didefinisikan sebagai suatu nilai yang dibahas berikut ini. Matriks $\mathbf{P}_{i j}$ dinamakan sebagai rotasi Givens, yang merupakan sebuah matriks yang ortogonal [2]. Penggunaan matriks $\mathbf{P}_{i j}$ untuk merotasi $\mathbf{0} \neq \boldsymbol{x} \in \mathbb{R}^{n}$ terhadap koordinat$(i, j)$ menghasilkan:

$$
\mathbf{P}_{i j} \boldsymbol{x}=\left(\begin{array}{c}
x_{1} \\
\vdots \\
c x_{i}+s x_{j} \\
\vdots \\
-s x_{i}+c x_{j} \\
\vdots \\
x_{n}
\end{array}\right) \leftarrow j
$$

Misalkan $x_{i}$ dan $x_{j}$ keduanya tidak nol, dan dituliskan sebagai berikut,

maka

$$
c=\frac{x_{i}}{\sqrt{x_{i}^{2}+x_{j}^{2}}} \text { dan } s=\frac{x_{j}}{\sqrt{x_{i}^{2}+x_{j}^{2}}}
$$

$$
\mathbf{P}_{i j} \boldsymbol{x}=\left(\begin{array}{c}
x_{1} \\
\vdots \\
\sqrt{x_{i}^{2}+x_{j}^{2}} \\
\vdots \\
0 \\
\vdots \\
x_{n}
\end{array}\right) \leftarrow i
$$

Berdasarkan hal analisis pada $\mathbf{P}_{i j} \boldsymbol{x}$, maka dapat dipilih sebarang komponen yang ingin dijadikan bernilai nol, yang dalam kasus ini adalah $x_{j}$, tanpa mempengaruhi entri selain $x_{i}$ dan $x_{j}$. Hasil dari rotasi bidang selalu merupakan matriks ortogonal [2].

\section{PENERAPAN TRANSFORMASI GIVENS PADA DEKOMPOSISI QR}

Dekomposisi QR, atau dapat pula disebut faktorisasi QR, merupakan bentuk pemfaktoran dari sebuah matriks berukuran $m \times n$. Untuk memperjelas mengenai dekomposisi $\mathrm{QR}$, berikut diberikan definisi dari dekomposisi QR.

Definisi 2 [3] Dekomposisi $Q R$ dari sebuah matriks $\mathbf{A} \in \mathbf{M}_{m \times n}(\mathbb{R})$ adalah faktorisasi dari $\mathbf{A}=\mathbf{Q R}$ dengan $\mathbf{Q} \in \mathbf{M}_{m \times m}(\mathbb{R})$ adalah matriks ortogonal $\left(\mathbf{Q}^{-1}=\mathbf{Q}^{T}\right)$ dan $\mathbf{R} \in \mathbf{M}_{m \times n}(\mathbb{R})$ adalah matriks segitiga atas $\left(\mathbf{R}=\left[r_{i j}\right]\right.$ dengan $r_{i j}=0$ untuk $\left.i>j\right)$.

Terdapat beberapa cara yang dapat digunakan untuk membentuk dekomposisi QR ini. Satu di antara cara yang dapat digunakan adalah dengan menggunakan Rotasi Givens [4]. 
Misalkan terdapat matriks $\mathbf{A} \in \mathbf{M}_{m \times n}(\mathbb{R})$ yang ditentukan dekomposisinya. Misalkan $\mathbf{A}_{1}=\mathbf{A}$. Tentukan matriks rotasi Givens terhadap entri $a_{(m-1) 1}$ dan $a_{m 1}$ yang dinamai sebagai $\mathbf{P}_{1}$. Matriks $\mathbf{P}_{1}$ digunakan untuk menjadikan entri $a_{m 1}$ bernilai nol. Kalikan kedua matriks $\mathbf{P}_{1}$ dan $\mathbf{A}$, dituliskan sebagai berikut

$$
\mathbf{A}_{2}=\mathbf{P}_{1} \mathbf{A}_{1}
$$

Kemudian tentukan matriks rotasi Givens $\mathbf{P}_{2}$ terhadap entri $a_{(m-2) 1}$ dan $a_{(m-1) 1}$. Matriks $\mathbf{P}_{2}$ digunakan untuk menjadikan entri $a_{(m-1) 1}$ bernilai nol. Tuliskan perkalian $\mathbf{P}_{2}$ dan $\mathbf{A}_{2}$ sebagai berikut

$$
\mathbf{A}_{3}=\mathbf{P}_{2} \mathbf{A}_{2}=\mathbf{P}_{2} \mathbf{P}_{1} \mathbf{A}
$$

Selanjutnya, ditentukan kembali matriks rotasi Givens $\mathbf{P}_{3}$ dan seterusnya sampai entri-entri pada kolom satu di bawah diagonal utama $a_{11}$ bernilai nol. Setelah entri di bawah $a_{11}$ seluruhnya bernilai nol, selanjutnya dilanjutkan ke kolom dua untuk menjadikan entri di bawah $a_{22}$ seluruhnya bernilai nol. Begitu seterusnya sampai $\mathbf{P}_{k}$ menjadikan seluruh entri di bawah diagonal utama bernilai nol. Secara umum dapat dituliskan sebagai berikut

$$
\mathbf{A}_{k+1}=\mathbf{P}_{k} \mathbf{A}_{k}=\mathbf{P}_{k} \ldots \mathbf{P}_{2} \mathbf{P}_{1} \mathbf{A}
$$

Matriks $\mathbf{A}_{k+1}$ membentuk matriks segitiga atas yang kemudian dinamakan matriks $\mathbf{R}$ atau dituliskan

$$
\mathbf{P}_{k} \ldots \mathbf{P}_{2} \mathbf{P}_{1} \mathbf{A}=\mathbf{R}
$$

Kemudian misalkan $\mathbf{P}_{k} \ldots \mathbf{P}_{2} \mathbf{P}_{1}=\mathbf{P}$. Karena $\mathbf{P}_{i}$, dengan $i=1, \ldots, k$, merupakan matriks rotasi Givens, maka $\mathbf{P}_{i}$ merupakan matriks ortogonal. Matriks $\mathbf{P}$ merupakan perkalian dari matriks-matriks yang ortogonal. Akan ditunjukkan jika $\mathbf{P}_{i}$ dan $\mathbf{P}_{j}$ ortogonal, dengan $1 \leq i, j \leq k$, maka perkaliannya juga ortogonal sebagai berikut

$$
\begin{aligned}
\left(\mathbf{P}_{a} \mathbf{P}_{b}\right)^{-1} & =\mathbf{P}_{b}^{-1} \mathbf{P}_{a}^{-1} \\
& =\mathbf{P}_{b}^{T} \mathbf{P}_{a}^{T} \\
& =\left(\mathbf{P}_{a} \mathbf{P}_{b}\right)^{T}
\end{aligned}
$$

Bedasarkan persamaan (1), maka dapat dituliskan persamaan sebagai berikut

$$
\begin{aligned}
\mathbf{P A} & =\mathbf{R} \\
\mathbf{P}^{-1} \mathbf{P A} & =\mathbf{P}^{-1} \mathbf{R} \\
\mathbf{A} & =\mathbf{P}^{T} \mathbf{R}
\end{aligned}
$$

Matriks $\mathbf{P}^{T}$ kemudian disebut sebagai matriks $\mathbf{Q}$ yang diperoleh dari matriks berikut

$$
\mathbf{Q}=\mathbf{P}^{T}=\mathbf{P}_{1}^{T} \mathbf{P}_{2}^{T} \ldots \mathbf{P}_{k}^{T}
$$

Berdasarkan penjabaran diperoleh dekomposisi dari matriks $\mathbf{A}$, dituliskan $\mathbf{A}=\mathbf{Q R}$.

Contoh 3 Didefinisikan matriks A sebagai berikut.

$$
\mathbf{A}=\left(\begin{array}{ccc}
2 & 1 & 1 \\
1 & 3 & 2 \\
-1 & 1 & 2
\end{array}\right)
$$

Dilakukan perhitungan untuk menentukan dekomposisi QR dari matriks A. Matriks A dikalikan dengan matriks rotasi Givens untuk membentuk matriks segitiga atas. Entri yang harus dijadikan nol yaitu entri $a_{31}, a_{21}$, dan $a_{32}$. Sebagai tahap pertama, yang dijadikan nol adalah entri $c_{31}$, kemudian dilanjutkan dengan entri $c_{21}$ dan $c_{32}$ sebagai berikut.

$$
\mathbf{A}_{2}=\mathbf{P}_{1} \mathbf{A}=\left(\begin{array}{ccc}
1 & 0 & 0 \\
0 & 0,71 & -0,71 \\
0 & 0,71 & 0,71
\end{array}\right)\left(\begin{array}{ccc}
2 & 1 & 1 \\
1 & 3 & 2 \\
-1 & 1 & 2
\end{array}\right)=\left(\begin{array}{ccc}
2 & 1 & 1 \\
1,41 & 1,41 & 0 \\
0 & 2,83 & 2,83
\end{array}\right)
$$

Selanjutnya dilakukan perkalian untuk menjadikan entri $c_{21}$ bernilai nol sebagai berikut.

$$
\mathbf{A}_{3}=\mathbf{P}_{2} \mathbf{A}_{2}=\left(\begin{array}{ccc}
0,82 & 0,58 & 0 \\
-0,58 & 0,82 & 0 \\
0 & 0 & 1
\end{array}\right)\left(\begin{array}{ccc}
2 & 1 & 1 \\
1,41 & 1,41 & 0 \\
0 & 2,83 & 2,83
\end{array}\right)=\left(\begin{array}{ccc}
2,45 & 1,63 & 0,83 \\
0 & 0,58 & -0,58 \\
0 & 2,83 & 2,83
\end{array}\right)
$$

Selanjutnya dilakukan perkalian untuk menjadikan entri $c_{32}$ bernilai nol sebagai berikut.

$$
\mathbf{A}_{4}=\mathbf{P}_{3} \mathbf{A}_{3}=\left(\begin{array}{ccc}
1 & 0 & 0 \\
0 & 0,2 & 0,98 \\
0 & -0,98 & 0,2
\end{array}\right)\left(\begin{array}{ccc}
2,45 & 1,63 & 0,83 \\
0 & 0,58 & -0,58 \\
0 & 2,83 & 2,83
\end{array}\right)=\left(\begin{array}{ccc}
2,45 & 1,63 & 0,83 \\
0 & 2,89 & 2,66 \\
0 & 0 & 1,13
\end{array}\right)=\mathbf{R}
$$

Kemudian karena matriks $\mathbf{A}_{4}$ yang dihasilkan telah membentuk matriks segitiga atas, maka telah diperoleh matriks $\mathbf{R}$. Selanjutnya ditentukan matriks $\mathbf{Q}$ dengan mengalikan transpose dari matriks $\mathbf{P}_{1}$ sampai $\mathbf{P}_{3}$ sebagai berikut. 


$$
\begin{aligned}
\mathbf{P}_{1}^{T} \mathbf{P}_{2}^{T} & =\left(\begin{array}{ccc}
1 & 0 & 0 \\
0 & 0,71 & 0,71 \\
0 & -0,71 & 0,71
\end{array}\right)\left(\begin{array}{ccc}
0,82 & -0,58 & 0 \\
0,58 & 0,82 & 0 \\
0 & 0 & 1
\end{array}\right)=\left(\begin{array}{ccc}
0,82 & -0,58 & 0 \\
0,41 & 0,58 & 0,71 \\
-0,41 & -0,58 & 0,71
\end{array}\right) \\
\mathbf{P}_{1}^{T} \mathbf{P}_{2}^{T} \mathbf{P}_{3}^{T} & =\left(\begin{array}{ccc}
0,82 & -0,58 & 0 \\
0,41 & 0,58 & 0,71 \\
-0,41 & -0,58 & 0,71
\end{array}\right)\left(\begin{array}{ccc}
1 & 0 & 0 \\
0 & 0,2 & -0,98 \\
0 & 0,98 & 0,2
\end{array}\right)=\left(\begin{array}{ccc}
0,82 & -0,12 & 0,57 \\
0,41 & 0,81 & -0,42 \\
-0,41 & 0,58 & 0,71
\end{array}\right)=\mathbf{Q}
\end{aligned}
$$

Telah diperoleh matriks $\mathbf{Q}$ dan $\mathbf{R}$. Selanjutnya, dilakukan perkalian untuk menguji apakah $\mathbf{Q R}=\mathbf{A}$ sebagai berikut.

$$
\mathbf{Q R}=\left(\begin{array}{ccc}
0,82 & -0,12 & 0,57 \\
0,41 & 0,81 & -0,42 \\
-0,41 & 0,58 & 0,71
\end{array}\right)\left(\begin{array}{ccc}
2,45 & 1,63 & 0,83 \\
0 & 2,89 & 2,66 \\
0 & 0 & 1,13
\end{array}\right)=\left(\begin{array}{ccc}
2 & 1 & 1 \\
1 & 3 & 2 \\
-1 & 1 & 2
\end{array}\right)=\mathbf{A}
$$

Sehingga benar bahwa $\mathbf{A}$ dapat dinyatakan sebagai $\mathbf{A}=\mathbf{Q R}$.

\section{PENERAPAN TRANSFORMASI GIVENS PADA NILAI EIGEN}

Terdapat banyak cara yang bisa digunakan untuk menentukan nilai eigen. Namun, satu di antara metode terbaik untuk menentukan nilai eigen dari suatu matriks persegi yaitu dengan menggunakan Algoritma QR [5]. Berikut dijelaskan mengenai Algoritma QR.

Misalkan diberikan matriks $\mathbf{A} \in \mathbf{M}_{n \times n}(\mathbb{R})$. Kemudian matriks $\mathbf{A}$ difaktorkan menjadi $\mathbf{Q}_{1} \mathbf{R}_{1}$, dengan $\mathbf{Q}_{1}$ matriks ortogonal dan $\mathbf{R}_{1}$ matriks segitiga atas. Definisikan

$$
\mathbf{A}_{1}=\mathbf{A}=\mathbf{Q}_{1} \mathbf{R}_{1}
$$

Persamaan $\mathbf{A}_{1}=\mathbf{Q}_{1} \mathbf{R}_{1}$ dapat dijabarkan sebagai berikut

$$
\begin{aligned}
\mathbf{A} & =\mathbf{Q}_{1} \mathbf{R}_{1} \\
\mathbf{Q}_{1}^{-1} \mathbf{A} & =\mathbf{Q}_{1}^{-1} \mathbf{Q}_{1} \mathbf{R}_{1}
\end{aligned}
$$

karena $\mathbf{Q}$ adalah matriks ortogonal, maka $\mathbf{Q}^{-1}=\mathbf{Q}^{T}$ sehingga

$$
\mathbf{Q}_{1}^{T} \mathbf{A}_{1}=\mathbf{R}_{1}
$$

Selanjutnya untuk memperoleh $\mathbf{A}_{2}$ dilakukan sebagai berikut

$$
\mathbf{A}_{2}=\mathbf{Q}_{1}^{T} \mathbf{A} \mathbf{Q}_{1}=\mathbf{R}_{1} \mathbf{Q}_{1}
$$

Faktor $\mathbf{A}_{2}$ dapat dituliskan sebagai $\mathbf{Q}_{2} \mathbf{R}_{2}$, dengan $\mathbf{Q}_{2}$ merupakan matriks yang ortogonal dan $\mathbf{R}_{2}$ merupakan matriks segitiga atas. Selanjutnya didefinisikan

$$
\mathbf{A}_{3}=\mathbf{Q}_{2}^{T} \mathbf{A}_{2} \mathbf{Q}_{2}=\mathbf{R}_{2} \mathbf{Q}_{2}=\left(\mathbf{Q}_{1} \mathbf{Q}_{2}\right)^{T} \mathbf{A}\left(\mathbf{Q}_{1} \mathbf{Q}_{2}\right)
$$

Dapat diperhatikan bahwa $\mathbf{A}_{2}=\mathbf{Q}_{1}^{T} \mathbf{A} \mathbf{Q}_{1}$ dan $\mathbf{A}_{3}=\left(\mathbf{Q}_{1} \mathbf{Q}_{2}\right)^{T} \mathbf{A}\left(\mathbf{Q}_{1} \mathbf{Q}_{2}\right)$ keduanya menggunakan matriks $\mathbf{A}$. Secara umum matriks $\mathbf{A}_{k}$ dituliskan sebagai

Kemudian, untuk $\mathbf{A}_{k+1}$ didefinisikan sebagai

$$
\mathbf{A}_{k}=\mathbf{Q}_{k} \mathbf{R}_{k}
$$

$$
\mathbf{A}_{k+1}=\mathbf{R}_{k} \mathbf{Q}_{k}=\mathbf{Q}_{k}^{T} \mathbf{A}_{k} \mathbf{Q}_{k}
$$

Secara umum, urutan matriks yang didefinisikan dengan $\mathbf{A}_{k+1}$ akan membentuk matriks berikut

$$
\left(\begin{array}{cccc}
B_{1} & \times & \cdots & \times \\
0 & B_{2} & & \vdots \\
\vdots & \ddots & \ddots & \times \\
0 & \cdots & 0 & B_{n}
\end{array}\right)
$$

dengan $B_{1}, B_{2}, \ldots, B_{n}$ adalah entri pada diagonal utama yang merupakan nilai eigen dari A. Pada Algoritma QR ini digunakan transformasi Givens dalam proses pengerjaannya yaitu menggunakan matriks $\mathbf{P}_{i j}$.

Contoh 4 Diberikan sebuah matriks persegi sebagai berikut

$$
\mathbf{A}=\left(\begin{array}{ccc}
2 & 1 & 1 \\
1 & 3 & 2 \\
-1 & 1 & 2
\end{array}\right)
$$

Ditentukan nilai eigen dari matriks A dengan menggunakan nilai eigen.

Pertama-tama dihitung nilai $c$ dan $s$ untuk matriks $\mathbf{P}_{1}$ sebagai berikut. 


$$
c=\frac{1}{\sqrt{(-1)^{2}+1^{2}}}=\frac{1}{\sqrt{2}} \approx 0,71
$$

dan

$$
s=\frac{-1}{\sqrt{(-1)^{2}+1^{2}}}=\frac{-1}{\sqrt{2}} \approx-0,71
$$

Kemudian dibentuk matriks $\mathbf{P}_{1}$ dan transpose-nya sebagai berikut.

$$
\mathbf{P}_{1}=\left(\begin{array}{ccc}
1 & 0 & 0 \\
0 & 0,71 & -0,71 \\
0 & 0,71 & 0,71
\end{array}\right) \text { dan } \mathbf{P}_{1}^{T}=\left(\begin{array}{ccc}
1 & 0 & 0 \\
0 & 0,71 & 0,71 \\
0 & -0,71 & 0,71
\end{array}\right)
$$

Kemudian dikalikan dengan matriks $\mathbf{A}_{1}=\mathbf{A}$ sebagai berikut

$$
\begin{aligned}
& \mathbf{A}_{2}=\mathbf{P}_{1} \mathbf{A}_{1} \mathbf{P}_{1}^{T}=\left(\begin{array}{ccc}
1 & 0 & 0 \\
0 & 0,71 & -0,71 \\
0 & 0,71 & 0,71
\end{array}\right)\left(\begin{array}{ccc}
2 & 1 & 1 \\
1 & 3 & 2 \\
-1 & 1 & 2
\end{array}\right)\left(\begin{array}{ccc}
1 & 0 & 0 \\
0 & 0,71 & 0,71 \\
0 & -0,71 & 0,71
\end{array}\right) \\
& =\left(\begin{array}{ccc}
2 & 1 & 1 \\
1,41 & 1,41 & 0 \\
0 & 2,83 & 2,83
\end{array}\right)\left(\begin{array}{ccc}
1 & 0 & 0 \\
0 & 0,71 & 0,71 \\
0 & -0,71 & 0,71
\end{array}\right)=\left(\begin{array}{ccc}
2 & 0 & 1,41 \\
1,41 & 1 & 1 \\
0 & 0 & 4
\end{array}\right) \\
& \mathbf{A}_{3}=\mathbf{P}_{2} \mathbf{A}_{2} \mathbf{P}_{2}^{T}=\left(\begin{array}{ccc}
0,82 & 0,58 & 0 \\
-0,58 & 0,82 & 0 \\
0 & 0 & 1
\end{array}\right)\left(\begin{array}{ccc}
2 & 0 & 1,41 \\
1,41 & 1 & 1 \\
0 & 0 & 4
\end{array}\right)\left(\begin{array}{ccc}
0,82 & -0,58 & 0 \\
0,58 & 0,82 & 0 \\
0 & 0 & 1
\end{array}\right) \\
& =\left(\begin{array}{ccc}
2,45 & 0,58 & 1,73 \\
0 & 0,82 & 0 \\
0 & 0 & 4
\end{array}\right)\left(\begin{array}{ccc}
0,82 & -0,58 & 0 \\
0,58 & 0,82 & 0 \\
0 & 0 & 1
\end{array}\right)=\left(\begin{array}{ccc}
2,33 & -0,94 & 1,73 \\
0,47 & 0,67 & 0 \\
0 & 0 & 4
\end{array}\right) \\
& \mathbf{A}_{4}=\left(\begin{array}{ccc}
0,98 & 0,20 & 0 \\
-0,20 & 0,98 & 0 \\
0 & 0 & 1
\end{array}\right)\left(\begin{array}{ccc}
2,33 & -0,94 & 1,73 \\
0,47 & 0,67 & 0 \\
0 & 0 & 4
\end{array}\right)\left(\begin{array}{ccc}
0,98 & -0,20 & 0 \\
0,20 & 0,98 & 0 \\
0 & 0 & 1
\end{array}\right) \\
& =\left(\begin{array}{ccc}
2,38 & -0,79 & 1,70 \\
0,00 & 0,84 & -0,34 \\
0,00 & 0,00 & 4,00
\end{array}\right)\left(\begin{array}{ccc}
0,98 & -0,20 & 0 \\
0,20 & 0,98 & 0 \\
0 & 0 & 1
\end{array}\right) \\
& =\left(\begin{array}{ccc}
2,18 & -1,25 & 1,70 \\
0,17 & 0,82 & -0,34 \\
0,00 & 0,00 & 4,00
\end{array}\right) \\
& \mathbf{A}_{5}=\left(\begin{array}{cccc}
1,00 & 0,08 & 0 \\
-0,08 & 1,00 & 0 \\
0 & 0 & 1
\end{array}\right)\left(\begin{array}{ccc}
2,18 & -1,25 & 1,70 \\
0,17 & 0,82 & -0,34 \\
0,00 & 0,00 & 4,00
\end{array}\right)\left(\begin{array}{ccc}
1,00 & -0,08 & 0 \\
0,08 & 1,00 & 0 \\
0 & 0 & 1
\end{array}\right) \\
& =\left(\begin{array}{ccc}
2,18 & -1,18 & 1,67 \\
0,00 & 0,92 & -0,47 \\
0,00 & 0,00 & 4,00
\end{array}\right)\left(\begin{array}{ccc}
1,00 & -0,08 & 0 \\
0,08 & 1,00 & 0 \\
0 & 0 & 1
\end{array}\right) \\
& =\left(\begin{array}{ccc}
2,09 & -1,34 & 1,67 \\
0,07 & 0,91 & -0,47 \\
0,00 & 0,00 & 4,00
\end{array}\right) \\
& \mathbf{A}_{6}=\left(\begin{array}{ccc}
1,00 & 0,03 & 0 \\
-0,03 & 1,00 & 0 \\
0 & 0 & 1
\end{array}\right)\left(\begin{array}{ccc}
2,09 & -1,34 & 1,67 \\
0,07 & 0,91 & -0,47 \\
0,00 & 0,00 & 4,00
\end{array}\right)\left(\begin{array}{ccc}
1,00 & -0,03 & 0 \\
0,03 & 1,00 & 0 \\
0 & 0 & 1
\end{array}\right) \\
& =\left(\begin{array}{ccc}
2,09 & -1,31 & 1,65 \\
0,00 & 0,96 & -0,53 \\
0,00 & 0,00 & 4,00
\end{array}\right)\left(\begin{array}{ccc}
1,00 & -0,03 & 0 \\
0,03 & 1,00 & 0 \\
0 & 0 & 1
\end{array}\right) \\
& =\left(\begin{array}{ccc}
2,04 & -1,38 & 1,65 \\
0,03 & 0,96 & -0,53 \\
0,00 & 0,00 & 4,00
\end{array}\right) \\
& \mathbf{A}_{7}=\left(\begin{array}{ccc}
1,00 & 0,02 & 0 \\
-0,02 & 1,00 & 0 \\
0 & 0 & 1
\end{array}\right)\left(\begin{array}{ccc}
2,04 & -1,38 & 1,65 \\
0,03 & 0,96 & -0,53 \\
0,00 & 0,00 & 4,00
\end{array}\right)\left(\begin{array}{ccc}
1,00 & -0,02 & 0 \\
0,02 & 1,00 & 0 \\
0 & 0 & 1
\end{array}\right) \\
& =\left(\begin{array}{ccc}
2,04 & -1,37 & 1,64 \\
0,00 & 0,98 & -0,55 \\
0,00 & 0,00 & 4,00
\end{array}\right)\left(\begin{array}{ccc}
1,00 & -0,02 & 0 \\
0,02 & 1,00 & 0 \\
0 & 0 & 1
\end{array}\right)
\end{aligned}
$$




$$
\begin{aligned}
& =\left(\begin{array}{ccc}
2,02 & -1,40 & 1,64 \\
0,02 & 0,98 & -0,55 \\
0,00 & 0,00 & 4,00
\end{array}\right) \\
& \mathbf{A}_{8}=\left(\begin{array}{ccc}
1,00 & 0,01 & 0 \\
-0,01 & 1,00 & 0 \\
0 & 0 & 1
\end{array}\right)\left(\begin{array}{ccc}
2,02 & -1,40 & 1,64 \\
0,02 & 0,98 & -0,55 \\
0,00 & 0,00 & 4,00
\end{array}\right)\left(\begin{array}{ccc}
1,00 & -0,01 & 0 \\
0,01 & 1,00 & 0 \\
0 & 0 & 1
\end{array}\right) \\
& =\left(\begin{array}{ccc}
2,02 & -1,39 & 1,64 \\
0,00 & 0,99 & -0,57 \\
0,00 & 0,00 & 4,00
\end{array}\right)\left(\begin{array}{ccc}
1,00 & -0,01 & 0 \\
0,01 & 1,00 & 0 \\
0 & 0 & 1
\end{array}\right) \\
& =\left(\begin{array}{ccc}
2,01 & -1,41 & 1,64 \\
0,01 & 0,99 & -0,57 \\
0,00 & 0,00 & 4,00
\end{array}\right) \\
& \mathbf{A}_{9}=\left(\begin{array}{cccc}
1,00 & 0,004 & 0 \\
-0,004 & 1,00 & 0 \\
0 & 0 & 1
\end{array}\right)\left(\begin{array}{ccc}
2,01 & -1,41 & 1,64 \\
0,01 & 0,99 & -0,57 \\
0,00 & 0,00 & 4,00
\end{array}\right)\left(\begin{array}{ccc}
1,00 & -0,004 & 0 \\
0,004 & 1,00 & 0 \\
0 & 0 & 1
\end{array}\right) \\
& =\left(\begin{array}{ccc}
2,01 & -1,40 & 1,64 \\
0,00 & 0,99 & -0,57 \\
0,00 & 0,00 & 4,00
\end{array}\right)\left(\begin{array}{ccc}
1,00 & -0,004 & 0 \\
0,004 & 1,00 & 0 \\
0 & 0 & 1
\end{array}\right) \\
& =\left(\begin{array}{ccc}
2,01 & -1,41 & 1,64 \\
0,004 & 0,99 & -0,57 \\
0,00 & 0,00 & 4,00
\end{array}\right) \\
& \mathbf{A}_{10}=\left(\begin{array}{cccc}
1,00 & 0,002 & 0 \\
-0,002 & 1,00 & 0 \\
0 & 0 & 1
\end{array}\right)\left(\begin{array}{ccc}
2,01 & -1,41 & 1,64 \\
0,004 & 0,99 & -0,57 \\
0,00 & 0,00 & 4,00
\end{array}\right)\left(\begin{array}{ccc}
1,00 & -0,002 & 0 \\
0,002 & 1,00 & 0 \\
0 & 0 & 1
\end{array}\right) \\
& =\left(\begin{array}{ccc}
2,01 & -1,41 & 1,63 \\
0,00 & 1,00 & -0,57 \\
0,00 & 0,00 & 4,00
\end{array}\right)\left(\begin{array}{ccc}
1,00 & -0,002 & 0 \\
0,002 & 1,00 & 0 \\
0 & 0 & 1
\end{array}\right)=\left(\begin{array}{ccc}
2,00 & -1,41 & 1,63 \\
0,00 & 1,00 & -0,57 \\
0,00 & 0,00 & 4,00
\end{array}\right) .
\end{aligned}
$$

Karena matriks $\mathbf{A}_{10}$ telah membentuk matriks segitiga atas, maka perhitungan dicukupkan dan telah diperoleh nilai eigen dari matriks $\mathbf{A}$. Nilai eigen dari matriks $\mathbf{A}$ terdapat pada entri diagonal utama matriks $\mathbf{A}_{10}$. Sehingga diperoleh nilai eigen dari matriks $\mathbf{A}$ yaitu $\lambda_{1}=2, \lambda_{2}=1$, dan $\lambda_{3}=4$.

\section{KESIMPULAN}

Berdasarkan uraian yang telah dipaparkan, maka dapat ditarik kesimpulan sebagai berikut.

1. Matriks rotasi yang diperluas menjadi dimensi- $n$ dikenal sebagai matriks rotasi Givens. Matriks rotasi Givens memenuhi definisi dari transformasi linear, sehingga kemudian dapat disebut sebagai transformasi Givens. Matriks rots Givens dituliskan sebagai berikut.

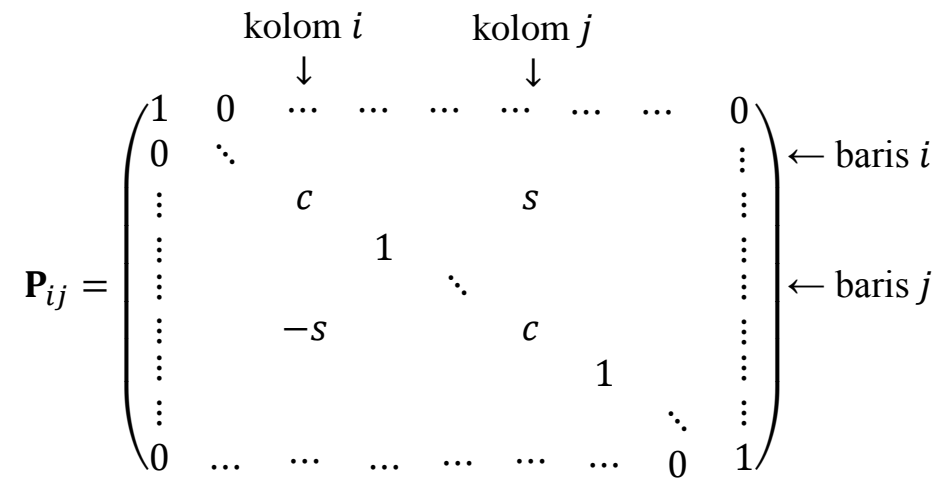

dengan $c=\frac{x_{i}}{\sqrt{x_{i}^{2}+x_{j}^{2}}}, s=\frac{x_{j}}{\sqrt{x_{i}^{2}+x_{j}^{2}}}$ dan entri selain diagonal utama, $c$, dan $s$ bernilai nol.

2. Dekomposisi QR dari suatu matriks dapat ditentukan dengan menggunakan transformasi Givens. Matriks $\mathbf{R}$ diperoleh dengan persamaan $\mathbf{R}=\mathbf{P}_{k} \ldots \mathbf{P}_{2} \mathbf{P}_{1} \mathbf{A}$ dan matriks $\mathbf{Q}$ diperoleh dengan $\mathbf{Q}=\mathbf{P}_{1}^{T} \mathbf{P}_{2}^{T} \ldots \mathbf{P}_{k}^{T}$. 
3. Nilai eigen dari suatu matriks persegi diperoleh dengan menggunakan Algoritma QR dengan matriks $\mathbf{P}$ dengan persamaan $\mathbf{A}_{k+1}=\mathbf{P}_{k} \mathbf{A}_{k} \mathbf{P}_{k}^{T}$

\section{DAFTAR PUSTAKA}

[1] Howard A. dan Chris R. Elementary Linear Algebra: Applications Version. Edisi kesebelas. Wiley; 2013.

[2] Carl DM. Matrix Analysis and Applied Linear Algebra. Carolina Utara; 2000.

[3] Rosen KH. Handbook of Linear Algebra Discrete Mathematics and Its Applications. Edisi kedua. Taylor \& Francis Group; 2014.

[4] Jim L. The QR Factorization. Summer Session. Lecture 9 Notes; 2009.

[5] Steven JL. Linear Alebra with Applications. Edisi kedelapan. Pearson; 2010.

DWI OKTAVIANA : Jurusan Matematika FMIPA Untan, Pontianak, dwioktaviana97@student.untan.ac.id

EVI NOVIANI : Jurusan Matematika FMIPA Untan, Pontianak, evi_noviani@math.untan.ac.id

FRANSISKUS FRAN : Jurusan Matematika FMIPA Untan, Pontianak, fransiskusfran@math.untan.ac.id 